\title{
Aurelio de los Reyes García Rojas (coord.), Miradas al cine mexicano (vols. 1 y 2), Instituto Mexicano de Cinematografía, Ciudad de México, 419 y 417 pp., 2016.
}

ISBN:978-607-965-283-8; ISBN: 978-607-965-284-5

\author{
Llamil Mena-Brito Sánchez**
}

Hablar de los estudios fílmicos en México es reconocer una larga y próspera tradición de investigaciones y especialistas que, a pesar de no partir de una formación curricular específica como la de investigadores de otros países, han escrito, desde hace ya más de cincuenta años, la historia del cine mexicano partiendo de una amplia gama de disciplinas. Los dos volúmenes de Miradas al Cine Mexicano son un rico y suntuoso ejemplo de esta tradición, que hoy y ante el beneplácito de muchos ante la anhelada creación de la licenciatura en cinematografía de la Universidad Nacional Autónoma de México, demuestra la excelente salud que goza la investigación cinematográfica mexicana de la mano de diversos profesionales de distintas generaciones e intereses a lo largo y ancho del país.

Aurelio de los Reyes, investigador y profesor emérito de la UNAM y coordinador de este proyecto bibliográfico, debe ser reconocido, entre otras muchas atribuciones, como el decano de la profesionalización de los estudios de cine en México. Ha trabajado muchas de las investigaciones fundacionales de la historiografía del cine mexicano y son muchos los estudiantes que han obtenido de él, sea en el aula o en sus libros, una educación que hace del cine tema fundamental para la comprensión de la sociedad y la cultura en México.

La escritura de la historia del cine mexicano encuentra en esta premisa la base de su institucionalización. Una sólida producción de investigaciones que partiendo de la multidisciplinariedad, destacando los estudios históricos y literarios, respondieron al fenómeno cinematográfico como uno que permitía contemplar una serie de continuidades en las problemáticas que impactaron

* Maestro en Historia del Arte, Universidad Nacional Autónoma de México. 
de manera trascendental a la cultura del siglo xx nacional, como por ejemplo la del nacionalismo. Para ello consideraron a las películas como documentos históricos de primera mano que desde la imagen y la palabra demostraban la permanencia de ésta y también la evolución de muchas otras problemáticas. Así pues, aunque la falta de una institucionalización de los estudios fílmicos en México repercutió en el desarrollo de la crítica cinematográfica y en el de la incursión de la teoría cinematográfica como modelo epistemológico, esta misma condición permitió a los investigadores del cine nacional eludir dos problemáticas inherentes a la historia de los estudios fílmicos universitarios. Por una parte, alejar de sus intereses fundamentales el debate sobre la hegemonía de una postura teórica sobre otra y, por otro lado, el predominio del análisis formalista que se decantara por un canon difícilmente sostenible en una filmografía tan compleja e inconsistente como la mexicana. Fue así como investigadores sociales en México establecieron desde sus propias metodologías científicas la comprensión del cine como un fenómeno eminentemente cultural e histórico, que no podía por principio ignorar o rechazar géneros, directores o producciones desde una evaluación estética, ya que la naturaleza del cine mexicano, al menos cuantitativamente, exige una comprensión cabal de sus momentos más virtuosos en íntima comunión con los más patéticos.

Miradas al Cine Mexicano es pues, un notable ejemplo de esta tradición y a la vez, un invaluable referente del progreso y la actualidad de los estudios sobre el cine en México en el nuevo milenio. Libro que, como bien enfatiza su coordinador, no se trata de una historia del cine en México, aunque sí puede funcionar por lo abarcante y profuso de su empresa, como un panorama cronológico de distintos momentos, temáticas y problemáticas inscritas en la historiografía del cine mexicano.

Esta panorámica parte del análisis de la transición del cine mudo al sonoro por distintas rutas que explican, en la concatenación del desarrollo tecnológico del cine con los eventos históricos paradigmáticos de los primeros treinta años del siglo xx en México, la evolución de una primera cinematografía mexicana marcadamente documentalista hasta la década de los veinte y en búsquedas de forma y fondo nacionalistas hasta bien entrada la década de los cuarenta. Los antecedentes de la Revolución mexicana y sus consecuencias, la relación política, económica y cultural con los Estados Unidos y la Guerra Cristera serán los contextos históricos que permitan desarrollar miradas generales en ensayos como "Del Cine Mudo al sonoro", de Aurelio de los Reyes; "La Revolución Mexicana en el cine", de Álvaro Vázquez Mantecón o "El cine mudo mexicano en Estados Unidos", de Rogelio Agrasánchez Jr.; planteamientos donde se proponga la resignificación de nociones como la del documental de la revolución mexicana (David Wood); o estudios que nos revelan desde la especificidad de su objeto de estudio, archivos poco conocidos y aún menos trabajados como el del cine pornográfico de la 
década de los veinte y treinta (Juan Solís) o el de la historia del periodismo y la bibliografía cinematográfica (Ángel Miquel).

A partir de este momento, la especificidad de intereses y la diversidad de perspectivas será la ruta que nos permita observar la compleja evolución del cine mexicano desde la constitución formal de su industria fílmica. Es así que ensayos que exploran aspectos técnicos como la música y el espacio geográfico y escenográfico en momentos específicos de la historia de nuestro cine, y aquellos que abordan el desarrollo de géneros como la comedia ranchera, el melodrama, el cine cómico, el cine fantástico y el de ciencia ficción, dan cuenta de los distintos intereses formales, ideológicos y comerciales en los que la producción deambuló por décadas buscando captar el gusto del público mexicano e internacional a la par de su propia búsqueda de estilo.

Un importante espacio dentro de estos dos volúmenes es concedido a temas que acontecieron fuera de la pantalla y que en buena medida definieron a la cultura cinematográfica mexicana. Las salas de exhibición como espacios de desarrollo arquitectónico y comunión social, la metamorfosis del cineclubismo y la influencia de éste para el desarrollo de la crítica cinematográfica y la producción independiente y experimental, y finalmente, las políticas cinematográficas gubernamentales y la relación de competitividad entre la industria mexicana y la de otras naciones son temáticas que nos permiten comprender, por su fuerte injerencia para el público, los creadores, la producción y la exhibición, la eventual crisis y la final desaparición de la industria cinematográfica mexicana.

Mención aparte merecen los ensayos que desde la perspectiva de género se incorporan al contenido de este libro. Con aportaciones de Julia Tuñón y Patricia Torres San Martín, referentes del análisis de género en la historia del cine nacional, Miradas al cine mexicano da espacio a diez ensayos que sin ser mucha la coincidencia, apuntan a la producción de la llamada "época de oro", momento paradigmático de la construcción más penetrante sobre la idea de lo femenino y masculino, el rol de género, y no menos importante, la articulación de la sexualidad filtrada a través de un complejo aparato moralista. La idea de lo femenino y el rol de la mujer en la sociedad fueron los aspectos que resintieron las repercusiones más aciagas de construcción de género dejando un legado de estereotipos sobre el rol de la mujer y la familia que perduró y sigue funcionando en distintos ámbitos de la cultura mexicana. En artículos que exploran al melodrama (Tunón), la figura de "la mujer nocturna" (Jesús Alberto Cabañas) y la de "la mujer audaz" (Torres San Martín) entramos de lleno en la construcción de estos estereotipos, en su permanencia en etapas posteriores a los años cuarenta y en el impacto que derivó de la construcción de la sexualidad en el cine a partir de ellos. La idea de la masculinidad, la sexualidad y la violencia y la teoría queer emergen como perspectivas teóricas y problemáticas necesarias para la comprensión 
de buena parte del peor cine mexicano, pero que de modo angustiante nos regresan a una noción de algo aún no superado del todo.

Son éstos, a grandes rasgos, los temas y problemáticas que en 35 ensayos escritos por 27 autores trazan este muestrario de "miradas" sobre la historia y el presente del cine mexicano. Miradas - como enfatiza el coordinadorpara incluir cualquier enfoque, metodología o visión de la mano de los principales estudiosos del cine en México.

Hoy, una nueva generación de estudiantes podrá gozar la oportunidad de estudiar al cine mexicano desde un plan curricular que haga al cine objeto central de su carrera y le ofrezca una metodología en consonancia con los estudios fílmicos internacionales. Otros profesionales continuarán desde diversas disciplinas la investigación de la historia del cine nacional. Sirvan a todos ellos estas Miradas al cine mexicano como una introducción y diagnóstico del estado de la investigación del cine mexicano y una invitación a participar en ella desde las omisiones que naturalmente este libro no pudo solventar. Para todos los demás, aquellos cinéfilos que simplemente buscan nutrir su interés por el séptimo arte, sepan que en estos libros seguramente hallarán la puerta para entrar a la historia del cine mexicano, una escrita con el mayor profesionalismo desde hace más de cincuenta años. Y sean estos libros también un aporte para el cine mexicano; un cine mexicano que parece necesitar muchas cosas, incluyendo lectores. 